\title{
MWCNTs/P(St-co-GMA) Composite Nanofibers of Engineered Interface Chemistry for Epoxy Matrix Nanocomposites
}

\author{
Elif Özden-Yenigün, Yusuf Z. Menceloğlu,* and Melih Papila \\ Sabanc1 University, Materials Science and Engineering, Advanced Composites and Polymer Processing Laboratory, 34956 Tuzla, \\ Istanbul, Turkey
}

\section{Supporting Information}

ABSTRACT: Strengthened nanofiber-reinforced epoxy matrix composites are demonstrated by engineering composite electrospun fibers of multi-walled carbon nanotubes (MWCNTs) and reactive $\mathrm{P}$ (St-co-GMA). MWCNTs are incorporated into surfacemodified, reactive $\mathrm{P}(\mathrm{St}-\mathrm{co}$-GMA) nanofibers by electrospinning; functionalization of these MWCNT/P(St-co-GMA) composite nanofibers with epoxide moieties facilitates bonding at the interface of the cross-linked fibers and the epoxy matrix, effectively reinforcing and toughening the epoxy resin. Rheological properties are determined and thermodynamic stabilization is demonstrated for MWCNTs in the $\mathrm{P}(\mathrm{St}-\mathrm{co}$ GMA)-DMF polymer solution. Homogeneity and uniformity of the fiber formation within the electrospun mats are achieved at

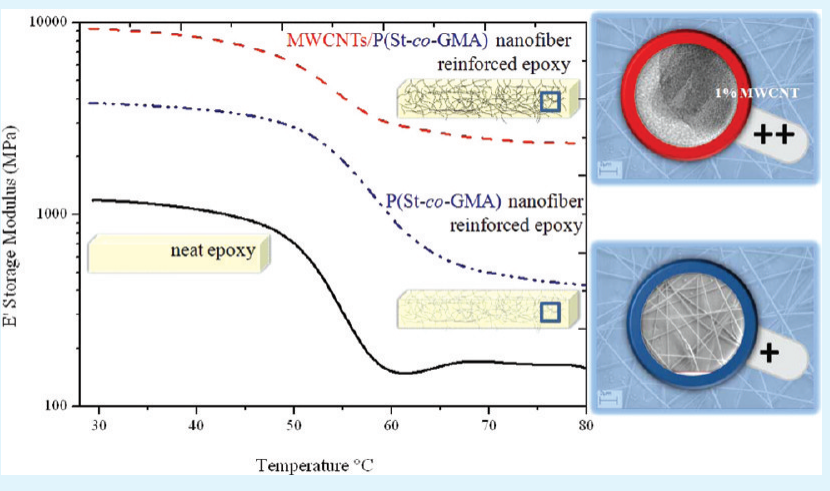
polymer concentration of $30 \mathrm{wt} \%$. Results show that the MWCNT fraction decreases the polymer solution viscosity, yielding a narrower fiber diameter. The fiber diameter drops from an average of $630 \mathrm{~nm}$ to $460 \mathrm{~nm}$, as the MWCNTs wt fraction (1, 1.5, and $2 \%)$ is increased. The electrospun nanofibers of the MWCNTs/P(St-co-GMA) composite are also embedded into an epoxy resin to investigate their reinforcing abilities. A significant increase in the mechanical response is observed, up to $>20 \%$ in flexural modulus, when compared to neat epoxy, despite a very low composite fiber weight fraction (at about $0.2 \%$ by a single-layer fibrous mat). The increase is attributed to the combined effect of the two factors the inherent strength of the well-dispersed MWCNTs and the surface chemistry of the electrospun fibers that have been modified with epoxide to enable cross-linking between the polymer matrix and the nanofibers.

KEYWORDS: electrospinning, composite nanofibers, surface modification, cross-linked interface, carbon nanotubes

\section{INTRODUCTION}

Since the discovery of carbon nanotubes $(\mathrm{CNTs}){ }^{1}$ they have attracted a lot of attention in materials and applied research because of their unique and fascinating structure and properties. $^{2-6}$ One specific application is the use of CNTs in polymer fibers to impart dramatically enhanced strength and toughness in the fibers. ${ }^{7-11}$ The incorporation of CNTs into the polymeric media via electrospinning, has been demonstrated to significantly improve the mechanical properties of the electrospun composite fibers. ${ }^{72-14}$ It is recognized that this technique is an ideal route to translate the unique superior properties of CNTs to mesoand macroscale structures ${ }^{7}$ by first embedding the CNTs in the fibers and then incorporating of these composite fibers into a polymer-matrix, successively.

Electrospinning is widely used process for forming ultrafine fibers by electrostatically induced self-assembly. ${ }^{15}$ One of the challenges of the electrospinning technique is controlling material and process parameters that affect the various properties and characteristics, such as overall strength, fiber diameter, and morphology. ${ }^{16}$ Electrospun polymeric nanofibers have recently been explored for their reinforcing ability in composites. ${ }^{17-22}$ They were utilized to specifically enhance the matrix-dominated mechanical properties of cross-linked polymer-matrix composites. ${ }^{2-24}$ Several researchers ${ }^{17,20,24}$ have studied the use of interfacial bonding to improve better mechanical performance, in nanostructure reinforced composites. In this application of polymer-matrix nanocomposites, our earlier experimental and computational studies ${ }^{1,24,25}$ demonstrated that the significant increase in the mechanical response is attributed to the combined effect of the two factors: the inherent cross-linked electrospun fiber structure and their surface chemistry lead to bonding at the interface between nanofibers and the cross-linked polymer-matrix.

In this study, the objective is to introduce CNTs into the nanofibers and nanocomposite system. The hypothesis herein is that it can be advantageous to electrospin reactive polymer nanofibers with CNTs to substantially improve the strength and toughness of composite nanofiber-reinforced epoxy due to both the inherent homogeneous distribution of CNTs and the affinity of the resultant composite fibers for epoxide group

\footnotetext{
Received: October 15, 2011

Accepted: January 16, 2012

Published: January 16, 2012
} 
functionalization. Our present experimental procedure began with exploring the effect of CNTs along with the polymer concentration during the electrospinning process. A factorial design of experiments (DOE) was performed to determine optimal set of parameters for polymer concentration and MWCNTs concentration for effective electrospun fibrous nanoreinforcement of the epoxy matrix. The composite nanofibers as determined by this DOE were characterized primarily to achieve reproducible nanofibrous mats. Next, the mechanical response and thermal stability were also investigated for the CNTs/ polymer nanofiber-reinforced epoxy matrix composites.

\section{EXPERIMENTAL SECTION}

Material Processing and Sample Production. Copolymer Synthesis. The monomers styrene (purified) and glycidylmethacrylate (GMA) were supplied by Aldrich Chemical Co, whereas the solvents, $N, N$ dimethylformamide and methanol, were purchased from Merck Chemicals Co. Copolymer P(St-co-GMA) was synthesized by solution polymerization technique. Purified styrene (90 wt \%) and GMA (10 wt \%) were put into a test tube in an ice bath. Dimethylformamide (DMF) was then added into St-GMA monomer mix so that volume proportion reaches 3:2, respectively. The initiator azobisisobutyronitrile (AIBN) was added to the test tube, after flushing with nitrogen. The tube containing the dissolved monomers was then held at $65^{\circ} \mathrm{C}$ in a thermal bath for $24 \mathrm{~h}$ for polymerization to take place. Finally, the polymer solution was poured into a beaker containing methanol and the methanol/polymer mixture was filtered and dried in an oven at $60{ }^{\circ} \mathrm{C}$ for $2 \mathrm{~h}$. The synthesized P(St-co-GMA) copolymer structure (see Figure 1) was determined by H-NMR. Molecular weights and

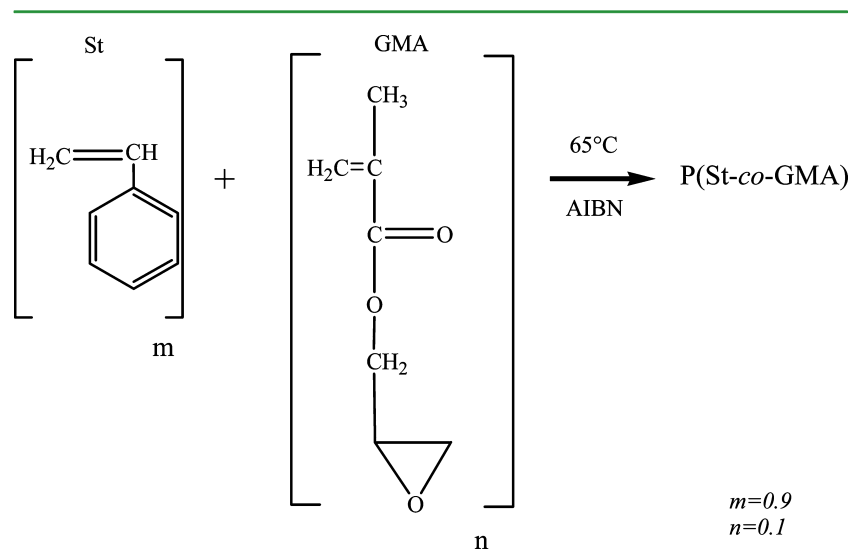

Figure 1. Chemical Structure of $\mathrm{P}($ St-co-GMA).

polydispersities were determined by gel permeation chromatography to be $160000 \mathrm{~g} / \mathrm{mol}$ and 1.35 PDI.

Electrospinning of $\mathrm{P}(\mathrm{St}-\mathrm{co}-\mathrm{GMA}) / \mathrm{MWCNTS}$ Nanofibers. $\mathrm{P}(\mathrm{St}-\mathrm{co}-$ GMA) was dissolved at three different concentrations 25, 27.5, and 30 wt \% in DMF. Multiwalled carbon nanotubes purity of $99 \%$ was then added to improve the mechanical properties of electrospun nanofibrous webs. The nominal diameter and length range of MWCNTs (Bayer Material Science-baytubes C150 HP) were 5-20 nm and 1-10 $\mu \mathrm{m}$, respectively. No surface modification on CNTs was employed in this work. They were dispersed in polymer solutions at different mass fractions/concentrations $(1,1.5$, and $2 \%)$ by mechanical stirring. With three levels of each variable, the polymer concentration and MWCNT mass fraction, a total of nine different combinations were used to produce nanofiber (Table 1 ). The solutions were stirred magnetically for another $24 \mathrm{~h}$ at room temperature, to ensure homogeneity. The polymer solutions with dispersed MWCNTs were then electrospun to produce the non-woven fiber mats. An electrical bias potential (Gamma High Voltage ES 30P-20W) was applied to the polymer solutions, which were contained in a $2 \mathrm{~mL}$ syringe.An alligator clip attached to the syringe needle (diameter $300 \mu \mathrm{m}$ ) enabled biasing of
Table 1. Electrospun Composite Nanofibers by $\mathbf{P}($ St-coGMA) and MWCNTs and Their Assignment for Nanocomposites

\begin{tabular}{cccc} 
run & $\begin{array}{c}\text { polymer } \\
\text { concentration (wt \%) }\end{array}$ & $\begin{array}{c}\text { MWCNT } \\
\text { concentration }(\%)\end{array}$ & $\begin{array}{c}\text { nanofiber reinforced } \\
\text { composites }\end{array}$ \\
\hline 1 & 25 & 1 & NO \\
2 & 25 & 1.5 & NO \\
3 & 25 & 2 & NO \\
4 & 27.5 & 1 & NO \\
5 & 27.5 & 1.5 & NO \\
6 & 27.5 & 2 & NO \\
7 & 30 & 1 & YES \\
8 & 30 & 1.5 & YES \\
9 & 30 & 2 & YES \\
\hline
\end{tabular}

the solution. The applied voltage was adjusted to $15 \mathrm{kV}$, while the grounded collector covered with aluminum foil was placed $10 \mathrm{~cm}$ away from the syringe needle tip. A syringe pump (NewEra NE-1000 Syringe Pump) was used to maintain a solution flow rate of $30 \mu \mathrm{L} / \mathrm{h}$ during electrospinning.

Preparation of Nanofiber-Reinforced Composites for DMA Testing. The experiments for electrospun MWCNTs/P(St-co-GMA) composite nanofiber processing are summarized in Table 1, along with the designation of candidates for embedding in an epoxy matrix. The nanofiber mats were first cut into $12 \mathrm{~mm} \times 50 \mathrm{~mm}$ pieces. The mean specific surface area of a typical electrospun fiber mat layer in this work is approximately $32.2 \mathrm{~g} / \mathrm{m}^{2}$, obtained when electrospinning $2 \mathrm{~mL}$ of polymer solution. Next, the fiber mats with thickness around $30 \mu \mathrm{m}$ were embedded into epoxy resin (Hunstman Adv. Mat. Co. Araldite LY 564 and XB 3404) layer by layer, using a Teflon mold custommade for the net-shape of DMA specimen. The epoxy matrix composites were reinforced by 1 and 10 layers of the fiber webs (corresponding approximately 0.2 and $2 \%$ fiber weight fraction) and were cured at $50^{\circ} \mathrm{C}$ for $15 \mathrm{~h}$, and then subsequently postcured at $80^{\circ} \mathrm{C}$ for $48 \mathrm{~h}$.

Materials Characterization. For characterizing the materials and processes in this work, a variety of techniques and equipments were used. Dynamic light scattering (DLS) measurements were carried out on Malvern Instrument DLS Zetasizer Nano ZS equipment to probe the hydrodynamic radii distribution of the MWCNTs, as a measure of the long term stability of electrospinning solutions. The effect of MWCNTs on viscosity of the solutions, a key factor in the electrospinning process, was elucidated by using a Malvern Bohlin $\mathrm{CVO}$ rotational rheometer. The shear viscosity of the solutions for the electrospinning process was measured at a range of control shear stresses of $10 \mathrm{~Pa}$ to $1000 \mathrm{~Pa}$. The morphologies of MWCNTs/P(St-coGMA) fibrous webs were evaluated by imaging using $2 \mathrm{keV}$ secondary electrons in field-emission gun equipped scanning electron microscope (FE-SEM, LEO 1530VP). In addition, the dispersion of MWCNTs on the nanofiber was evaluated by using HRTEM (JEOL 2100). The diameter of electrospun nanofibers was estimated by the image processing toolbox of MATLAB. The average fiber diameter and distribution were determined from about 25 measurements on the randomly selected fibers. Furthermore, drop shape analysis was performed to investigate the contact angle response of the webs for water and epoxy resin. The contact angles were measured on a Krüss GmbH DSA 10 Mk 2 goniometer with DSA 1.8 software. More than eight 5-mg droplets of distilled ultra-pure water and uncured epoxy resin/hardener mixture were averaged. To verify the presence of MWCNTs in the composite nanofiber mats,) we used the Raman spectroscopy ( Renishaw InVia Reflex Raman Microscopy System; Renishaw Plc., New Mills, Wotton-under-Edge Gloucestershire, UK. The $830 \mathrm{~nm}$ laser was used to probe structural response which was in the range $2000-500 \mathrm{~cm}^{-1}$. The thermo-mechanical behavior and characteristics of the MWCNTs/P(St-co-GMA) fiber-reinforced epoxy matrix composites were also explored: storage modulus was determined by using a dynamic mechanical thermal analyzer (Netzsch DMA 242). The DMA tests of nanofiber-reinforced hybrid materials 
along with the neat epoxy specimens were performed in three pointbending mode at a frequency of $1 \mathrm{~Hz}$ over a temperature range of 25$150^{\circ} \mathrm{C}$. The amplitude, maximum dynamic force and static constant force parameters were set as $30 \mu \mathrm{m}, 5 \mathrm{~N}$ and $0.01 \mathrm{~N}$, respectively. Five samples were tested for each DMA analysis. Finally, a universal testing machine (UTM, ZWICK Proline Z100) was used to determine flexural strength and flexural modulus at room temperature using the ASTM D790 standard. Eight samples were characterized for each UTM test.

\section{RESULTS AND DISCUSSION}

The electrospinning of polymer solutions containing MWCNTs is a complicated process. Specifically, suspending the CNTs in the polymer solution and ensuring the formation of homogenous stable suspensions prior to electrospinning are the frontline challenges. Therefore, we had initially focused on the dispersibility of MWCNTs in the solution. Furthermore, solution conductivity and suspension viscosity were investigated, as they are among the dominant factors in the electrospinning process. The design of experiment (DOE) approach was incorporated to identify and determine the significance of these process parameters in the production of uniform nanofibers. The existence of the MWCNTs in the composite fibers was demonstrated by TEM images and Raman spectroscopy. Electrospun webs of uniform fibrous morphology were used to reinforce epoxy matrix. Lastly, the mechanical response and thermal stability of the polymer composite nanofiber-reinforced nanocomposites were investigated.

Polymer Solution Characteristics. Stability of $a$ Polymer Solution Containing MWCNTs. In the electrospinning process, the characteristics of the initial solution determine the final composite fibrous structure and especially the diameter of the electrospun nanofibers. To determine the processing parameters to achieve stable and homogenous suspensions, a systematic study of DLS measurements was carried out. To monitor the system dynamics and the hydrodynamic radii distributions of a polymeric solution at $30 \mathrm{wt} \%$ concentration containing $1 \mathrm{wt} \%$ MWCNTs were determined at several time intervals: $1,2,4$, and $24 \mathrm{~h}$. The hydrodynamic radii at the initial stage exhibited three sharp peaks around 100, 300, and $1000 \mathrm{~nm}$, whereas the z-average particle size was $410 \mathrm{~nm}$. The consecutive experiments with a time interval of 1, 2, 4, and $24 \mathrm{~h}$ (See Fig 2) with the lack of mechanical driving forces revealed that agglomerates became stabilized based on the appropriate selection of polymer with styrene repeat unit and DMF as the solvent. Aromatic compounds, such as the benzene ring in our styrene are known to interact strongly with graphitic sidewalls of carbon nanotubes through effective $\pi-\pi$ stacking. ${ }^{26,27}$ These interactions are manifested in the dispersion of CNTs in aromatic solvents, ${ }^{28,29}$ as well as in solutions of certain polymers. ${ }^{30-34}$ The $\pi$-stacking interactions increase binding to CNTs, increasing as a consequence solubility of nanotubes in our polymer solution. ${ }^{35}$ In addition, the z-average particle size remained smaller than $580 \mathrm{~nm}$, even after $24 \mathrm{~h}$, and no precipitation was observed in the electrospinning solution. Increasing the MWCNTs concentration did not change the stabilization of the polymer. The largest hydrodynamic radii was still not higher than $1 \mu \mathrm{m}$ at $2 \%$ MWCNTs/P(St-co-GMA) solution. The size of the CNTs bundles did not vary in the subsequent hours because of the stabilization effect of the benzene ring in the polymer structure. Furthermore, $\mathrm{P}(\mathrm{St}-\mathrm{co}-\mathrm{GMA})$ has an aromatic ring that would assist in the long-term stabilization of MWCNTs in polymer solution during nanofiber formation. In fact, completely opaque solutions that are stable over the long term were achieved.

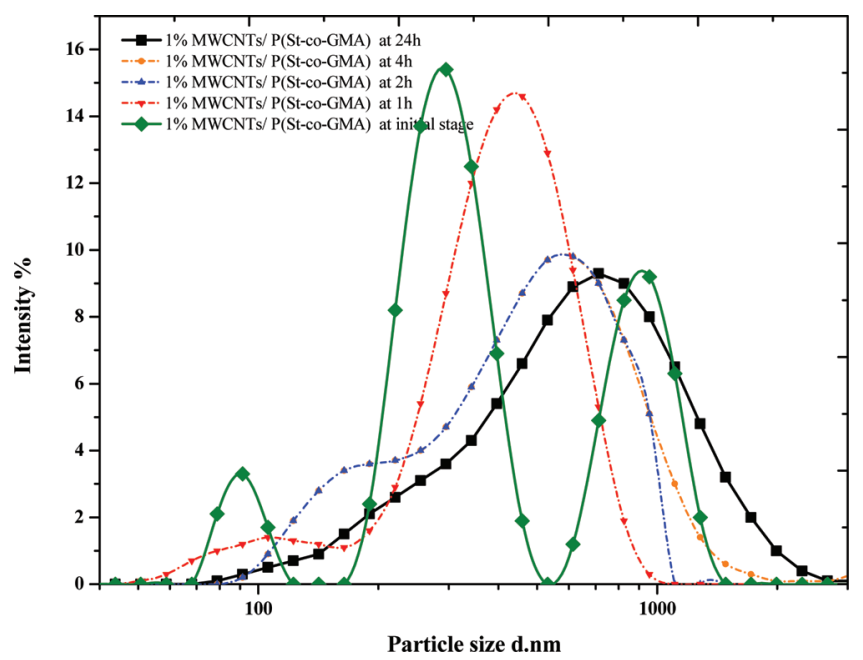

Figure 2. Hydrodynamic radii of the polymer solution at initial stage and after MWCNTs added. The times correspond to the delay after mixing: 1, 2, 4, and $24 \mathrm{~h}$; the z-average of electrospinning solutions at initial stage, 1, 2, 4, and $24 \mathrm{~h}$ were $410,505,510,520$, and $580 \mathrm{~nm}$, respectively.

Suspension Viscosity Characteristics by MWCNTs. Several factors related to the suspension viscosity (such as polymer concentration, particle/filler concentration, and the rheological behavior of the fine particle system) influence electrospinning process and the diameter of the fibers. Suspension viscosity should be examined, in order to discuss the flow behavior of solutions containing different amounts of MWCNTs under shear conditions, similar to those applied during the electrospinning process. Furthermore, as Park et $\mathrm{al}^{36}$ pointed out, the resultant shear stresses increases as the applied DC electric field increases in electrospinning. The measurements of shear viscosity in this research were conducted at different proportions of MWCNTs and neat $\mathrm{P}$ (St-co-GMA) in DMF solution. The results obtained show that viscosity decreases considerably with the addition of MWCNTs. Rotational rheometer results in Fig 3 reveal that at a shear stress of

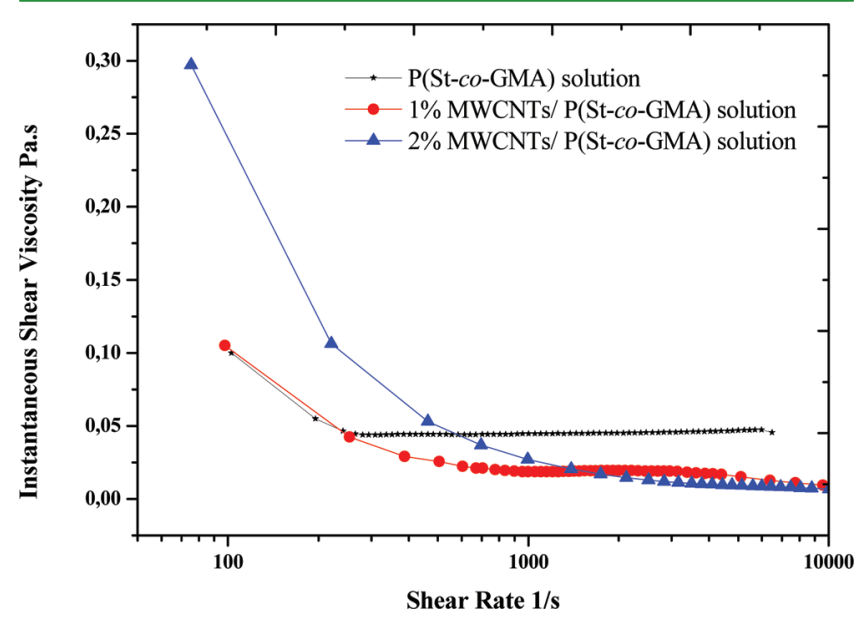

Figure 3. Suspension shear viscosity versus shear rate of neat polymer solutions and polymer solutions containing $1 \%$ and $2 \%$ of MWCNTs.

$10 \mathrm{~Pa}$, the shear viscosity of the neat polymer solution and the solution containing $1 \%$ MWCNTs were $9.98 \times 10^{-2} \mathrm{~Pa} \cdot \mathrm{s}$ and $10.50 \times 10^{-2} \mathrm{~Pa} \cdot \mathrm{s}$, respectively. Exceptionally, at shear stress $1000 \mathrm{~Pa}$, shear viscosity of the solutions dropped down to 
$47.14 \times 10^{-3} \mathrm{~Pa} \cdot \mathrm{s}$ and $8.76 \times 10^{-3} \mathrm{~Pa} \cdot \mathrm{s}$. Moreover, the shear viscosity of the polymer solutions containing $1 \%$ and $2 \%$ MWCNTs was also measured under the same conditions, and shear thinning behavior was observed in both solutions. The resultant shear viscosity at $1000 \mathrm{~Pa}$ dropped, to $8.76 \times 10^{-3} \mathrm{~Pa} \cdot \mathrm{s}$ and $6.73 \times$ $10^{-3} \mathrm{~Pa} \cdot \mathrm{s}$, correspondingly. The effect of suspension viscosity will be discussed further in the fiber morphology section.

Process Optimization for Composite Electrospun Nanofibers. Design of Experiment. Properties of the electrospun nanofiber formations, in particular the fiber diameter and morphology, depend on various parameters that can be divided into three groups: polymer solution properties (solution viscosity, solution concentration, polymer molecular weight, etc.); processing conditions (applied voltage, volume flow rate, etc.); and ambient conditions (temperature, humidity, etc.) In this study, processing and ambient conditions were held constant, in order to systematically investigate the effect of solution properties on the average fiber diameter. As observed in our previous studies, ${ }^{24}$ without the addition of MWCNTs, neat P(St-co-GMA) nanofibers were electrospun successfully at polymer concentrations of $30 \mathrm{wt} \%$ and higher. Here, polymer concentrations lower than $30 \mathrm{wt} \%$ and the addition of MWCNTs were considered, in order to investigate the possibility of spinning composite fibers with narrower fiber diameter. Three levels of polymer $(25,27.5$, and $30 \mathrm{wt} \%)$ and three levels of MWCNTs concentrations (1, 1.5, and 2 wt \%) resulted in nine possible combinations for factor setting (Table 2). A schematic of the experimental design is shown in Fig 4. The

\section{Table 2. Design of Experiment (Factors and Levels)}

\begin{tabular}{|ll}
\multicolumn{1}{|c}{ factor } & factor level \\
\hline polymer concentration (wt \%) & $25,27.5,30$ \\
MWCNTs concentration (wt \%) & $1,1.5,2$
\end{tabular}

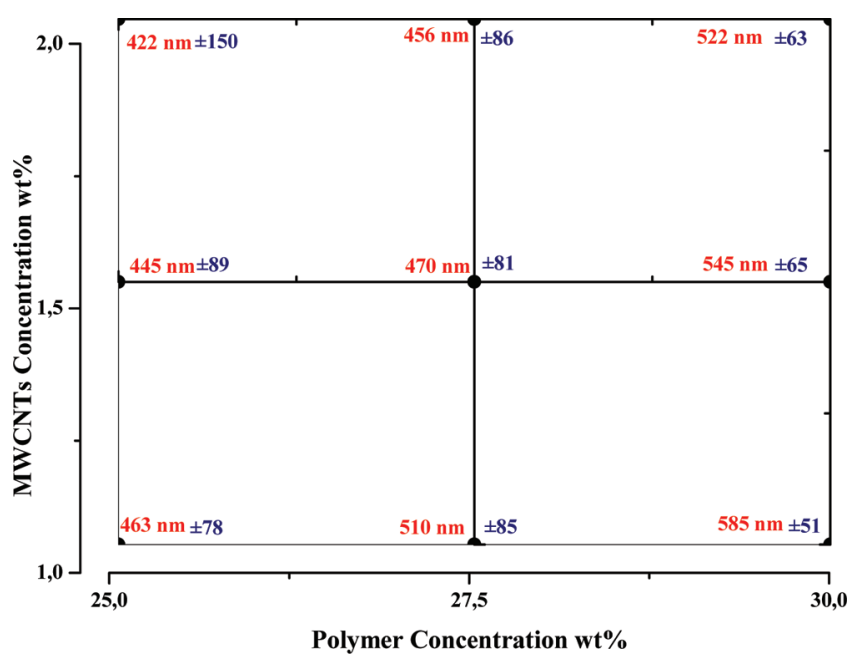

Figure 4. Experimental design. Red colored and blue colored values show the average fiber diameters $(\mathrm{nm})$ and the standard deviation of fiber diameter of about 25 measurements.

fibers were first electrospun under the same processing conditions, morphologies, and average diameters of the fibers were then investigated by SEM.

Morphology of Electrospun Fibers and Mats. Figure 5 shows the morphology of fibers obtained by varying the polymer and the MWCNTs concentration at $15 \mathrm{kV}$ and a constant collector distance of $10 \mathrm{~cm}$. The fiber diameter increased with polymer concentration, as anticipated, whereas fiber diameter decreased by tuning the MWCNT concentration. The effect on the fiber radii by MWCNTs is attributed to two factors: electrical conductivity ${ }^{11,37}$ and rheological changes in polymer solution (evidenced by reduced shear viscosity). It is widely known that the addition of MWCNTs increases the electrical conductivity of solutions (see Table 3 ). What is less acknowledged is that, depending on the surface and physical characteristic of particles, suspensions exhibit a range of rheological behavior that also influence the electrospinning process. Pseudoplastic materials, such as some polymer solutions, show signs of shear thinning behavior, which is an effect where viscosity decreases with increasing rate of shear stress. Moreover, shear thinning behavior would influence fiber diameter, as interpreted by Mazinani et al. ${ }^{37}$ as the break-up of the polymer chains during sonication. However, sonication was not applied in our case. Therefore, the reduced viscosity is attributed to the nanotube-polymer interaction under shear, which lead to the thinner nanofibers by electrospinning.

Using a polymer concentration of $25 \mathrm{wt} \%$ yielded thinner fibers (20 wt \% narrower compared to nanofibers at $30 \mathrm{wt} \%$ ), but less homogeneous nanowebs due to beadlike formations. Figure 6A suggests that the process resulted in spraying along with spinning, which prevented the formation of homogenous webs at 27.5 wt \% concentrations. In addition, branched nanofibers were observed (Figure 6B). These observations are consistent with our earlier work. ${ }^{24}$ Therefore, for further steps of hybrid material preparation, $30 \mathrm{wt} \%$ polymer concentrations were preferred for obtaining electrospun fiber and web homogeneity. It is worthy to note that increasing MWCNT concentration also led to the formation of beadlike structures (Fig 6C) and a high variance in the fiber diameter. Figure 5 suggested that at higher polymer concentration, MWCNTs concentration had more impact on the average fiber diameter than at lower polymer concentration. To summarize, the fiber diameter tends to increased with polymer concentration and decreased with MWCNTs concentration.

Detection of MWCNTs by TEM and Raman Spectroscopy. Raman spectra of non-woven mats were obtained using a red laser $(\lambda=830 \mathrm{~nm})$ for determining the signature of the MWCNTs. Among the characteristic peaks of MWCNTs detected by Raman spectroscopy using a red laser (see Figure 7), two peaks could be distinguished located at $1585 \mathrm{~cm}^{-1}(\mathrm{G})$ and around $1325 \mathrm{~cm}^{-1}$ (D).$^{38-40} \mathrm{P}$ (St-co-GMA) nanofibers themselves exhibit sharp peak around $1580 \mathrm{~cm}^{-1}$, which complicated determination of the MWCNT content. However, the peak at $1585 \mathrm{~cm}^{-1}$ for the composite nanofibers was a broader peak, when compared to the very narrow spectral feature of the neat polymeric nanofibers at this shift range, which is attributed to the existence of the MWCNTs. In addition, perturbations to the peaks are more distinctive for the $1 \%$-MWCNT and 2\%-MWCNT composite nanofibers, as the increasing MWCNTs concentration increased intensity and width of the peaks. Measurements from the surface of nanofibers demonstrated that it is possible to detect MWCNTs at such small amounts.

Evidence of the incorporation MWCNTs was also obtained by TEM imaging and their appearance within the polymer fiber were studied by HRTEM. Transmission electron microscopy observation of $1.0 \mathrm{wt} \% \mathrm{MWCNT} / \mathrm{P}$ (St-co-GMA) fibrous webs produced by electrospinning demonstrated that MWCNTs maintained their straight shape, even as they are positioned 


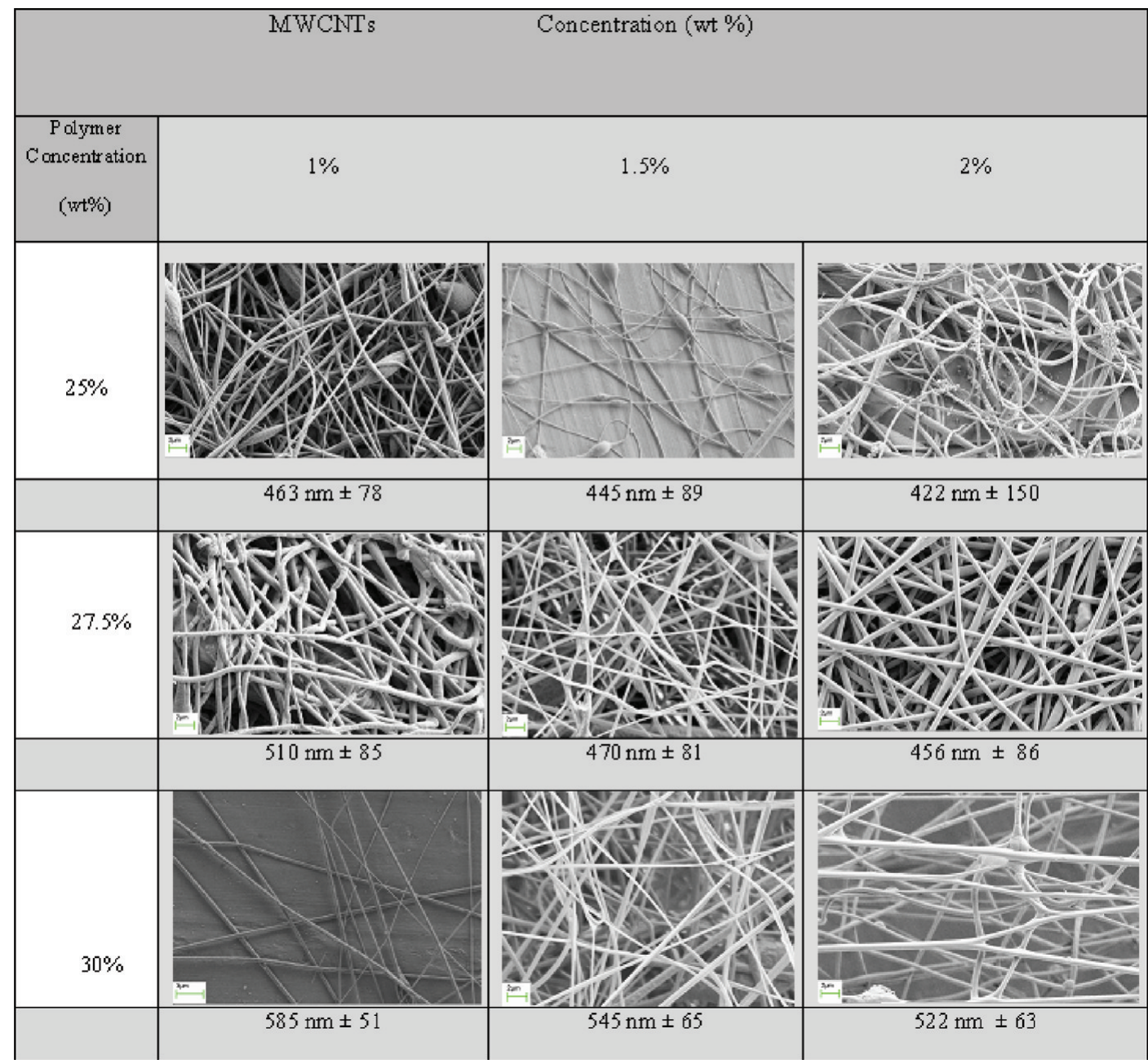

Figure 5. Morphology of fibers and average diameter with standard deviations at applied voltage $15 \mathrm{kV}$ by varying polymer and MWCNT concentration. The scale bars for fibers are $2 \mu \mathrm{m}$.

Table 3. Conductivity $(\mu \mathrm{S} / \mathrm{cm})$ of MWCNTs/30 wt \% P(Stco-GMA) Solutions at Different MWCNT Concentrations

\begin{tabular}{cccc} 
& \multicolumn{3}{c}{ MWCNT concentration (\%) } \\
\cline { 2 - 4 } & 1 & 1.5 & 2 \\
\hline conductivity $(\mu \mathrm{S} / \mathrm{cm})$ & 20.9 & 27.5 & 39.1
\end{tabular}

within the polymer fiber by electrospinning under an electrical potential (see Figure 8).

Surface Wettability of Nanofibrous Webs. The elevations formed by the fibers themselves, along with the inter-fiber porosity, contributed to a high degree of mesoscale roughness on the surface of electrospun nanowebs. Wettability of a rough surface was determined by the physical interaction between the solid surface and the particular liquid. Wenzel ${ }^{41}$ and Cassie-Baxter ${ }^{42}$ theories on the wettability of rough surfaces indicated that wetting was minimized due to roughness, if the contact between the solid and the liquid was not favored. For instance, the water contact angle on smooth $\mathrm{P}$ (St-co-GMA) surface prepared by dip coating was measured to be $97.4 \pm 2.77^{\circ}$, which indicated that the copolymer was hydrophobic. Accordingly, the rough nature of the electrospun surface increased this angle to $131.6 \pm 8.45^{\circ}$. On the other hand, wetting was induced because of roughness if the cohesive forces between the solid and liquid phases
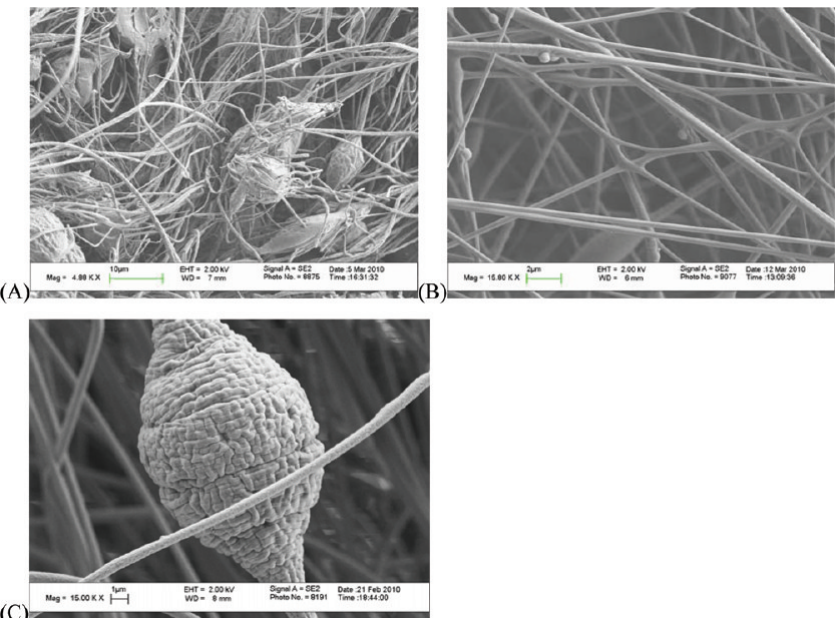

Figure 6. Morphology of nanofibers (A) at 25 wt \% polymer and 2\% MWCNT concentrations, partially sprayed inhomogeneous webs, (B) branched nanofibers at $27.5 \mathrm{wt} \%$, (C) magnified view of beadlike structures at 25 wt $\%$ polymer and $1 \%$ MWCNTs concentration.

dominated. The surface and chemical characteristics of functional MWCNTs/P(St-co-GMA) nanowebs were essential for the wettability by epoxy resin in structural composites. In order to determine the wettability of the electrospun mat by 


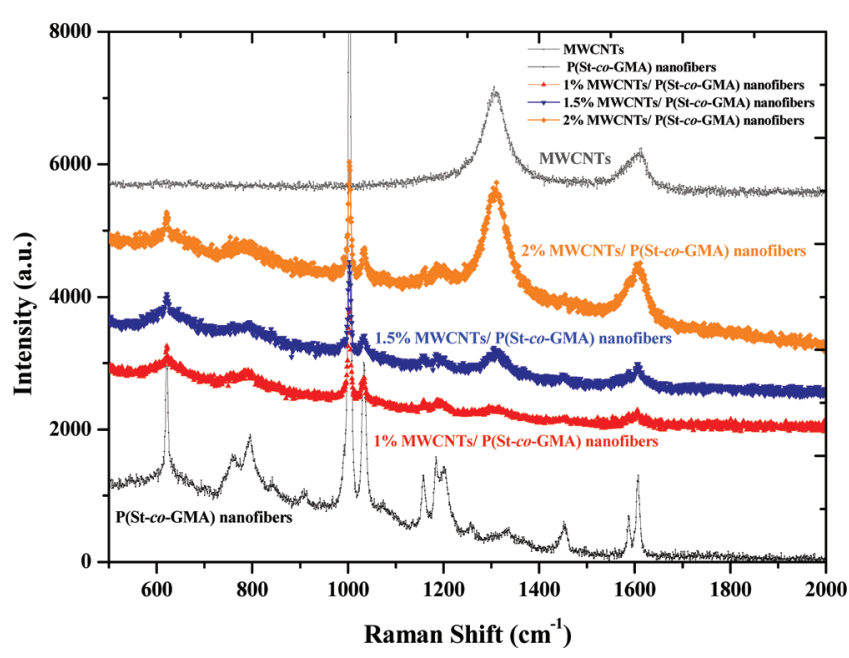

Figure 7. Raman Spectra of final nonwoven webs from red laser $830 \mathrm{~nm}$ $(300 \mathrm{~mW})$.

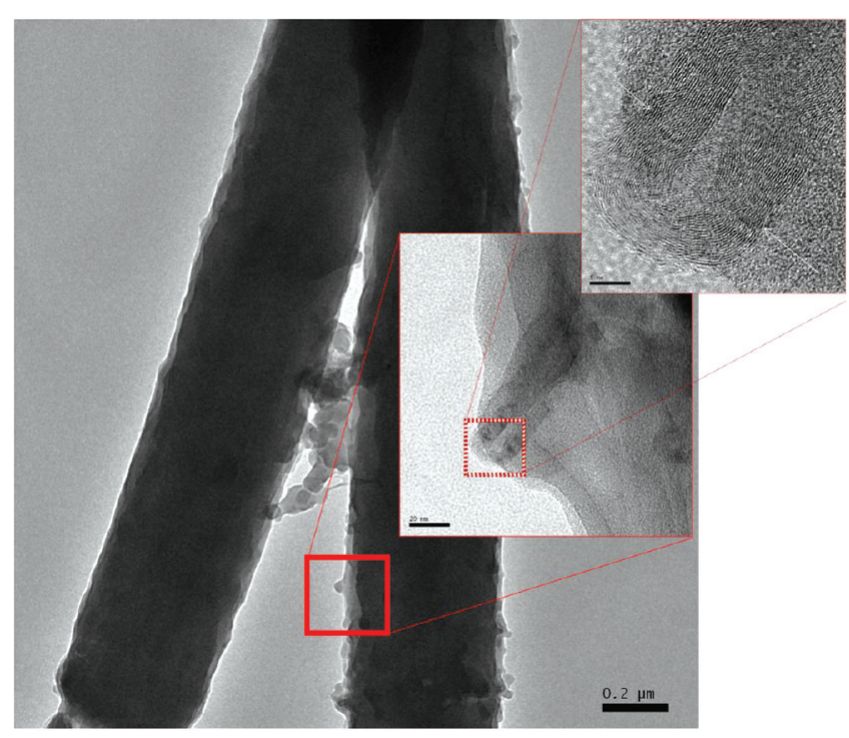

Figure 8. HRTEM of 1.0 wt \% multiwalled carbon nanotubes in P(Stco-GMA).

the resin, epoxy droplets were deposited on the surface of MWCNT/P(St-co-GMA) mat as shown in Figure 9, and eventually, the average contact angle was determined to be as

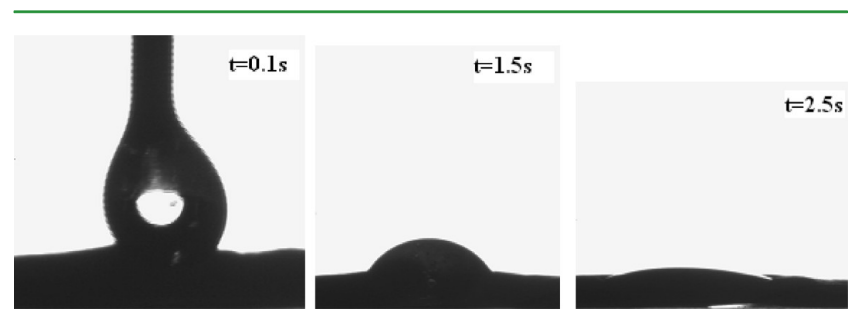

Figure 9. Frames recorded during DSA measurements. Average contact angle is $26.5 \pm 6.10^{\circ}$ for distilled epoxy droplet.

low as $26.5 \pm 6.10^{\circ}$. This result indicates that attractive forces between the copolymer and epoxy resin induced the liquid to spread over the rough surface and even penetrate the micropores without encountering a negative capillary pressure. Otherwise, high contact angles would be measured. Thus, the adhesion between epoxy resin and the nanofibrous MWCNTs/P(St-co-GMA) nano- web was high, which confirmed the physically stable epoxy-hybrid material system.

Mechanical Characterization of Composite Nanofiber-Reinforced Hybrid Materials. In our earlier studies $^{11,24}$ fiber-matrix interface strengthening was explored in reinforcing and toughening of the epoxy resin by the PStco-GMA nanofibers. Here MWCNTs were introduced into the fiber material system, as described in the section Electrospinning of $\mathrm{P}$ (St-co-GMA)/MWCNTs Nanofibers. After forming the composite nanofibers, their surface chemistry was similarly modified with epoxide moieties for strengthening the interface, ${ }^{24}$ were embedded into epoxy resin. Thermomechanical and mechanical properties of the nanocomposite were investigated so that an associated reinforcement due to the composite nanofibers electrospun at $30 \mathrm{wt} \%$ polymer concentration and various MWCNT fractions could be evaluated. The results compared to earlier the earlier study ${ }^{24}$ indicated that the incorporation of a $2 \%$ weight fraction of $1 \% \mathrm{MWCNT} / \mathrm{P}(\mathrm{St}$-co-GMA)-composite nanofibers in epoxy was remarkably effective in increasing the storage modulus of the composite at $30{ }^{\circ} \mathrm{C}$, i.e., there is more than a factor of 8 improvement relative to that of the neat epoxy. At $80{ }^{\circ} \mathrm{C}$ beyond the $T_{\mathrm{g}}$ of the composite material, the storage modulus reached a plateau, where the increase was around a factor of 18 compared to that of the neat epoxy (Figure 10A). In addition, thermomechanical tests revealed that embedding a single layer of composite web (i.e., yielding a $0.2 \%$ fiber weight fraction) improved the storage modulus of epoxy matrix nanocomposites with increasing MWCNTs concentration (Figure 10B). Specifically, MWCNTs/P(St-co-GMA) nanofibrous mats of $1 \%$, $1.5 \%$ and $2 \%$ CNT weight fraction, respectively, increased the room temperature storage modulus of the nanocomposites by 32 , 46 , and $69 \%$ and by 27,29 , and $34 \%$ at elevated temperature $150^{\circ} \mathrm{C}$ relative to that of the neat epoxy. The flexural strength $\left(S_{\mathrm{F}}\right)$ and flexural modulus $\left(E_{\mathrm{Y}}\right)$ of the neat resin and MWCNT/ $\mathrm{P}$ (St-co-GMA) nanofiber-reinforced hybrid materials were also measured at room temperature. ASTM- D790 3-point bending standard mechanical tests demonstrated that embedding a single layer of MWCNTs/P(St-co-GMA) nanofibrous mats of $1,1.5$, and $2 \% \mathrm{CNT}$ weight fraction increased the flexural modulus of the epoxy matrix nanocomposites (at $0.2 \%$ composite fiber weight fraction) $\left(E_{\mathrm{Y}}\right)$ by 22,23 , and $23 \%$, respectively, relative to that of the neat epoxy. Furthermore, the flexural strength $\left(S_{\mathrm{F}}\right)$ increased by 15,16 , and $18 \%$, respectively. As a reference point, earlier studies revealed that $S_{\mathrm{F}}$ and $E_{\mathrm{Y}}$, when reinforced at $0.2 \%$ mass fraction of $\mathrm{P}$ (St-co-GMA) nanofiber (no CNT addition), increased by $6^{11}$ and $16 \%{ }^{24}$ correspondingly. These comparative results suggested that increase in the strength was dominated by the polymer fibrous web, and existence of CNT at the fractions tested appeared to be ineffective for further increase. The increase in stiffness on the other hand was substantially enhanced, despite the low fraction of CNT introduced into the system. On the other hand, in our relevant work as Bilge et al., ${ }^{43,44}$ surface-reactive $\mathrm{P}(\mathrm{St}$-coGMA) and 1\% MWCNT/P(St-co-GMA) nanocomposite interlayers were introduced to the conventional carbon fiber/ epoxy prepregs by electrospinning. Use of the nanocomposite interlayers resulted in improvements in mechanical performance of composite laminates. The MWCNT-containing P(St-co-GMA) nanofibrous interlayers (denoted by $\mathrm{I}$ ) within the laminates $(0 /$ $\mathrm{I} / 0 / \mathrm{I} / 0)$ resulted in 11 and $17 \%$ increases in the flexural strength $\left(S_{\mathrm{F}}\right)$ and flexural modulus $\left(E_{\mathrm{Y}}\right)$, respectively. Introduction of nanotubes by $1 \mathrm{wt} \%$ to the copolymer fibers 

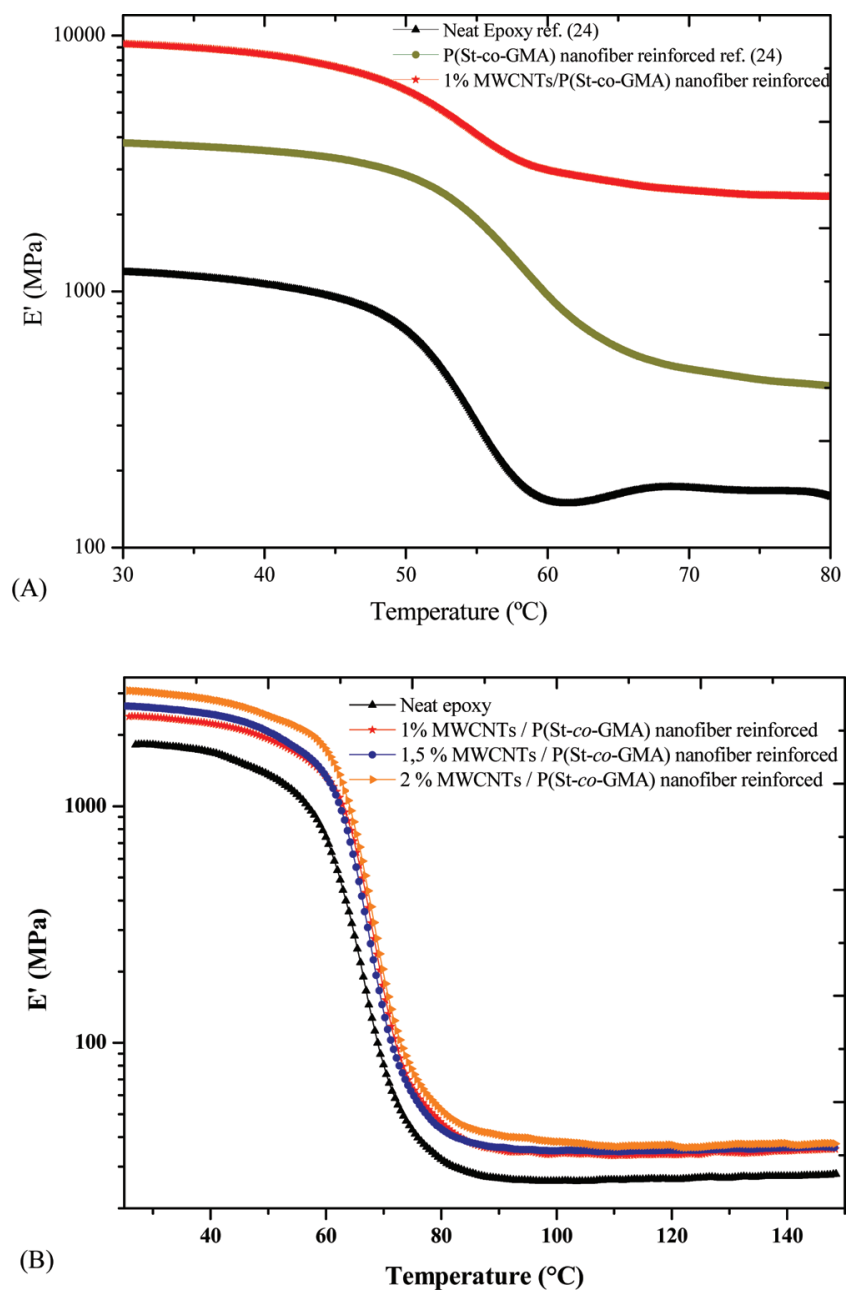

Figure 10. (A) Storage modulus vs temperature measurements on nanofiber-reinforced materials (reinforcement with ten layers of $1 \%$ MWCNTs/P(St-co-GMA) and P(St-co-GMA))webs and neat epoxy (B) Storage modulus vs temperature measurements on nanofiber reinforced hybrid materials (reinforcement with a single layer of MWCNTs/P(St-co-GMA) webs with 1, 1.5, and 2\% MWCNTs weight fractions) and neat epoxy.

led to a further improvement adding up to 16 and $25 \%$ increase in the corresponding values, compared to results without nanocomposite interlayers incorporated.

\section{CONCLUDING REMARKS}

Fiber-matrix interface strengthening was investigated by reinforcing and toughening of the epoxy resin by embedding carbon nanotubes in polymer nanofibers and by modifying the composite fiber surface chemistry to include epoxide rings. Specifically, MWCNT/P(St-co-GMA) composite nanofibers at three different nanotube weight fractions were electrospun in this work for the first time. Rheological properties and thermodynamic stabilization of MWCNTs in P(St-co-GMA)DMF polymer solution were demonstrated. The MWCNT fraction was found correlated with shear thinning effect and the corresponding drop in the polymer viscosity results in lower fiber diameter. It was also shown that electrospun fiber diameter can be reduced by directly lowering polymer concentration at several MWCNTs fraction, but at the cost of the homogeneity and uniformity of the fiber formation within the electrospun mats. A polymer concentration of $30 \mathrm{wt} \%$ was further studied, resulting in narrowing of the fiber diameter from an average 630 to $460 \mathrm{~nm}$, as MWCNT weight fraction (1, 1.5 and $2 \%)$ was increased. These electrospun MWCNTs/ $\mathrm{P}$ (St-co-GMA) composite nanofibers were then embedded into epoxy resin for exploring their reinforcing abilities. The significant increase was observed in the mechanical response up to $>20 \%$ in flexural modulus compared to neat epoxy despite a very low composite fiber weight fraction (at about $0.2 \%$ by a single-layer fibrous mat). The increase is attributed to the combined effect of the two factors: the strength of well dispersed MWCNTs in the structure and the modified surface chemistry of the electrospun fibers leading to bonding across the cross-linked polymer matrix-nanofiber interface. In fact, an increase in the flexural strength by nearly $15 \%$ due to composite nanofibers was also noted. However, the absence of perceptible variation by various fractions of the MWCNT suggested that the strength increase was primarily due to the existence of cross-linked polymer nanofiber and interface reinforcement.

\section{ASSOCIATED CONTENT}

\section{S Supporting Information}

This material is available free of charge via the Internet at http://pubs.acs.org.

\section{AUTHOR INFORMATION}

\section{Corresponding Author}

*E-mail: yusufm@sabanciuniv.edu.

\section{Present Address}

${ }^{\ddagger}$ Visiting Professor at Department of Aeronautics \& Astronautics, Stanford University, Stanford, CA

\section{ACKNOWLEDGMENTS}

E.Ö.-Y. acknowledges a TUBITAK BIDEB graduate student scholarship, and thanks Kaan Bilge for his cooperation in reinforcing study of nanowebs in structural composites, Eren Şimşek in helping to discuss roughness concept, Dr. Özgür Duygulu from TUBITAK-MAM for HR-TEM imaging, and Cleva Ow Yang for her scientific insight and proof reading.

\section{REFERENCES}

(1) Iijima, S. Nature 1991, 354, 56.

(2) Moniruzzaman, M; Winey, K.I. Macromolecules 2006, 39, 5194.

(3) Kymakis, E.; Amaratunga, G.A.J. Appl. Phys. Lett. 2002, 80, 112.

(4) Alexandrou, I; Kymakis, E; Amaratunga, G.A.J. Appl. Phys. Lett. 2002, 80, 1435

(5) Hughes, M; Shaffer, M.S.P.; Renouf, A.C; Singh, C; Chen, G.Z.; Fray, D.J.; Windle, A.H. Adv. Mater. 2002, 14, 382.

(6) Ago, H.; Pertritsch, K.; Shaffer, M.S.P.; Windle, A.H.; Friend, R.H. Adv. Mater. 1999, 11, 1281.

(7) Ko, F.; Gogotsi, Y.; Ali, A.; Naguib, N.; Ye, H.; Yang, G.L. Adv. Mater. 2003, 15, 1161.

(8) Ye, H.; Lam, H.; Titchenal, N.; Gogotsi, Y.; Ko, F. Appl Phys Lett. 2004, 85, 1775.

(9) Dror, Y.; Salalha, W.; Khalfin, R.L; Cohen, Y.; Yarin, A.L.; Zussman, E. Langmuir 2003, 19, 7012.

(10) Anderson, M.R; Mattes, B.R.; Reiss, H.; Kaner, R.B. Science 1991, 252, 1412

(11) Özden, E.; Menceloğlu, Y.Z.; Papila, M.; Lou, J.; Lilleodden, E.; Boyce, B.; Lu, L.; Derlet, P.M.; Weygand, D.; Li, J.; Uchic, M.D.; Le Bourhis, E. Mater. Res. Soc. Symp. Proc. 2010, 1224-FF10-23.

(12) Sen, R.; Zhao, B.; Perea, D.; Itkis, M.E.; Hu, H.; Love, J. Nano Lett. 2004, 4 (3), 459-464.

(13) Ge, J.J.; Hou, H.; Li, Q.; Graham, M.J.; Greiner, A.; Reneker, D.H. J. Am. Chem. Soc. 2004, 126, 15754. 
(14) Jose, M.V.; Steinert, B.W.; Thomas, V.; Dean, D.R.; Abdalla,

A.M.; Price, G.; Janowski, G.M. Polymer 2007, 48, 1096-1104.

(15) Reneker, D.; Chun, I. Nanotechnology 1996, 7, 216.

(16) Yordem, O.S.; Papila, M.; Menceloglu, Y.Z. Mater. Des. 2008, $29,34-44$.

(17) Uribe, A. R.; Arizmendi, L.; Guzman, M. E. R.; Guzman, S. S.; Silva, R. Appl. Mater. Interfaces 2009, 11, 2502-2508.

(18) Kim, J.S.; Reneker, D.H. Polym. Comp. 1999, 20, 124-131.

(19) Chen, G.; Liu, H. J. Appl. Polym. Sci 2008, 110, 641-646.

(20) Gao, Y.; Sagi, S.; Zhang, L.; Liao, Y.; Cowles, D. M.; Sun, Y.;

Fong, H. J. App. Polym. Sci. 2008, 110, 2063-2070.

(21) Han, S. O.; Son, W. K.; Youk, J. H.; Park, W. H. J. Appl. Polym. Sci. 2008, 107, 1954-1959.

(22) Bergshoef, M. M.; Vancso, G. J. Adv. Mater. 2000, 11, 16.

(23) Khojin, A. S.; Stone, J. J.; Zhong, W. H. J. Composite Mater. 2007, 41.

(24) Özden, E.; Menceloğlu, Y.Z.; Papila, M. ACS Appl. Mater. Interfaces 2010, 2 (7), 1788-1793.

(25) Özden, E.; Atilgan, A.R.; Bilge, K.; Menceloğlu, Y.Z.; Atılgan, C.; Papila, M. Mater. Res. Soc. Symp. Proc. 2011, 1304.

(26) Hunter, C. A.; Sanders, J. K. M. J. Am. Chem. Soc. 1990, 112, 5525.

(27) Zhao, J.; Lu, J. P.; Han, J.; Yang, C.-K. Appl. Phys. Lett. 2003, 82, 3746.

(28) Bahr, J. L.; Mickelson, E. T.; Bronikowski, M. J.; Smalley, R. E.; Tour, J. M. Chem. Commun. 2001, 193.

(29) Sun, Y.; Wilson, S.R.; Schuster, D. I. J. Am. Chem. Soc. 2001, 123, 5348.

(30) Star, A.; Stoddart, J. F.; Steuerman, D.; Diehl, M.; Boukai, A.; Wong, E.; Yang, X.; Chung, S.-W.; Choi, H.; Heath, J. R. Angew. Chem., Int. Ed. 2001, 40, 1721.

(31) O’Connell, M. J.; Boul, P.; Ericson, L. M.; Huffman, C.; Wang, Y. H.; Haroz, E.; Kuper, C.; Tour, J.; Ausman, K. D.; Smalley, R. E. Chem. Phys. Lett. 2001, 342, 265.

(32) Chen, J.; Lui, H.; Weimer, W. A.; Halls, M. D.; Waldeck, D. H.; Walker, G. C. J. Am. Chem. Soc. 2002, 124, 9034.

(33) Mitchell, C. A.; Bahr, J. L.; Arepalli, S.; Tour, J. M.; Krishnamoorti, R. Macromolecules 2002, 35, 8825.

(34) Star, A.; Liu, Y.; Grant, K.; Ridvan, L.; Stoddart, J. F.; Steuerman, D. W.; Diehl, M. Nano Lett. 2003, 3 (10), 1421-1423.

(35) Islam, M. F.; Rojas, E.; Bergey, D. M.; Johnson, A. T.; Yodh, A. G. Nano Lett. 2002, 3 (2), 269-273.

(36) Park, S. J.; Cho, M. S.; Lim, S. T.; Choi, H. J.; Jhon, M. S. Macromol. Rapid Commun. 2005, 26, 1563-1566.

(37) Mazinani, S.; Ajji, A.; Dubois, C. Polymer 2009, 50, 3329-3342.

(38) Antunes, F.F.; Lobo, A.O.; Corat, E.J.; Trava-Airoldi, VJ. Carbon 2003, 45 (5), 913-921.

(39) Corrias, M.; Serp, P.; Kalck, P.; Dechambre, G.; Lacout, J.L.; Castiglioini, C.; et al. Carbon 2003, 41 (12), 2361-2367.

(40) Duraia, E-S. M.; Burkitbaev, M.; Mohamedbakr, H.; Mansurov, Z.; Tokmolden, S.; Beall, G. W. Vacuum 2010, 84, 464-468.

(41) Wenzel, R. N. Ind. Eng. Chem. 1936, 28, 988.

(42) Cassie, A. B. D.; Baxter, S. Trans. Faraday Soc. 1944, 40, 546.

(43) Bilge K.; Özden E.; Şimşek E.; Menceloğlu Y.Z.; Papila M. Proceedings of the 18th International Conference on Composite Materials; Jeju Island, Korea, Aug 21-26, 2011 ; International Committee on Composite Materials, 2011.

(44) Bilge K.; Özden E.; Şimşek E.; Menceloğlu Y.Z.; Papila M. Compos. Sci. Eng., 2011, submitted. 